\title{
Escritores de Blogs: Interagindo com os Leitores ou Apenas Ouvindo Ecos?
}

Blog writers: interacting with readers or listening to echoes?
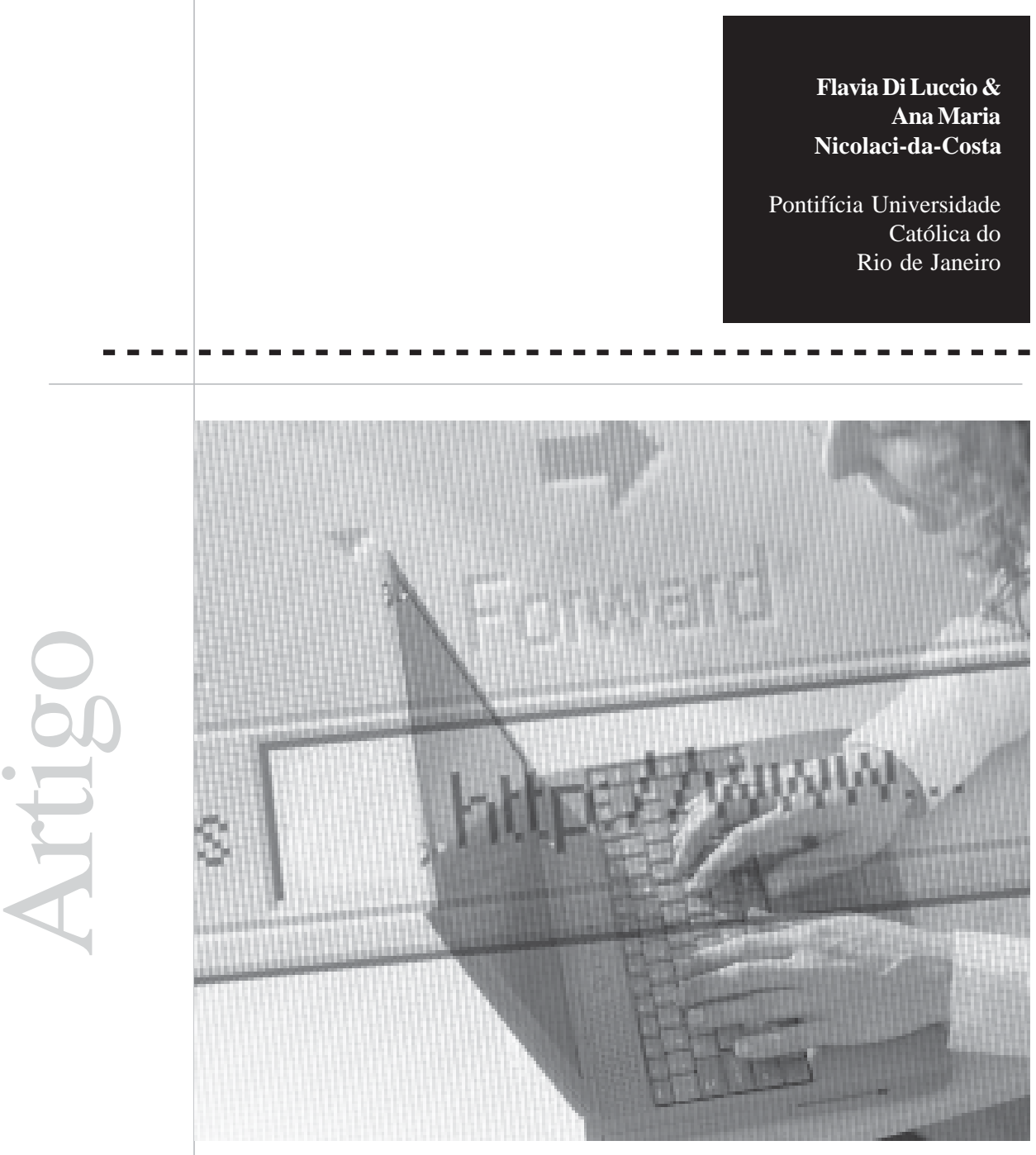


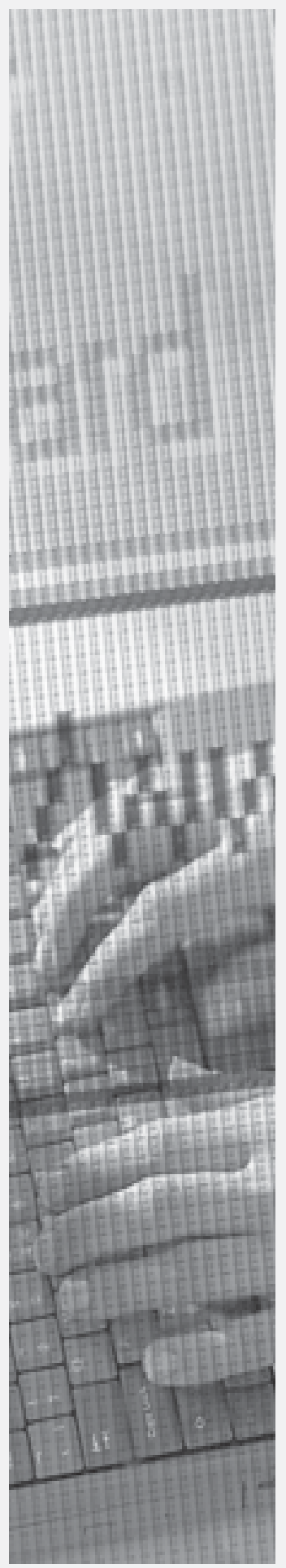

Resumo: Neste estudo, tivemos como objetivo investigar os impactos que a escrita digital e a tela do computador, como suporte textual, vêm tendo sobre escritores e leitores. As descrições que Roger Chartier faz dos três grandes cenários da escrita e da leitura que antecederam a era da escrita digital - aqueles marcados pelo rolo, pelo códice manuscrito e pelo livro impresso - serviram de contraponto para a avaliação desse novo tipo de escrita nesse novo suporte. Nossa análise se concentrou nesse quarto cenário e investigou uma de suas características inéditas: a de possibilitar a interação entre escritores e leitores nas telas de computadores conectados em rede. Para tanto, foi escolhido o espaço textual conhecido como weblog ou blog. O Método de Explicitação do Discurso Subjacente (MEDS) foi usado para realizar uma pesquisa na qual foram entrevistados autores de blogs atualizados regularmente. Embora, em um primeiro momento, os participantes tenham afirmado que sua decisão de criar e manter seus blogs estava ligada, sobretudo, à possibilidade de interação com os leitores, a análise mais minuciosa de seus depoimentos revelou um quadro diferente. Os entrevistados raramente interagem com seus leitores.

Palavras-chave: blogs, interação, escritores, leitores.

Abstract: The present study aimed at investigating the impacts that electronic writing and the computer screen as a medium for text transmission have on writers and readers. Roger Chartier's descriptions of the three important scenarios which anteceded the electronic writing era - those marked by the scroll, the handwritten codex and the printed book - were used as a comparative base for the evaluation of this new kind of writing on this new kind of medium. Our analysis concentrated on this fourth scenario and explored one of its unique characteristics: the one that enables the interaction between writers and readers on the screens of interconnected computers. In order to do so, we chose a textual space on the internet known as Weblog or blog. The Underlying Discourse Unveiling Method (UDVM) was used to conduct an investigation in which authors of regularly updated blogs were interviewed. Even though at first the authors had said that their decision to create and keep blogs was strictly connected to the possibility of interaction with the readers, a more detailed analysis of the interviews revealed a different picture. They hardly ever interact with their readers.

Key words: blogs, interaction, writers, readers. 
Ao longo dos séculos, desde a Antigüidade grega e romana até a contemporaneidade, novas tecnologias geraram diferentes suportes textuais que, por seu turno, deram origem a diversas "revoluções da escrita e da leitura" (Chartier, 1998, 1999, 2001, 2002).

Este trabalho tem por objetivo estudar o suporte textual gerado pelas tecnologias que caracterizam a mais recente dessas revoluções, a chamada “revolução digital”. Para tanto, em um primeiro momento, procura identificar os aspectos distintivos do novo suporte por elas produzido - a tela do computador - e comparar suas características com aquelas dos suportes que a antecederam. Assim sendo, neste primeiro momento, baseando-se na obra recente de Roger Chartier (1998, 1999, 2001, 2002), o presente estudo empreende uma visita aos quatro principais cenários de escrita e leitura ao longo da História, começando com os cenários mais antigos - que foram marcados, respectivamente, pelo rolo, pelo códice manuscrito e pelo livro impresso - e terminando com o cenário atual, o da tela do computador.

Indubitavelmente, um dos aspectos mais inovadores da tela do computador como suporte textual é a possibilidade de interação leitores-escritores, que faculta, em um segundo momento, o foco da presente discussão, estreita-se ainda mais e migra para o exame da relação entre leitores e escritores a partir das telas dos computadores conectados em rede.

\section{A escrita em quatro diferentes cenários}

O primeiro cenário a ser revisitado é o da Antigüidade grega e romana. Nesse período, os textos eram escritos em rolos, que consistiam de longas faixas de papiro (material feito de uma erva) ou pergaminho (feito da pele de cabra ou ovelha), que o leitor segurava com as duas mãos durante a leitura (Chartier, 1999). Os textos, manuscritos, eram dispostos horizontalmente no rolo e distribuídos em colunas. O leitor e o escritor desenrolavam o texto com a mão direita e enrolavam as partes lidas com a mão esquerda. Tal suporte acarretava limitações para os atos de escrever e de ler, já que tanto os leitores quanto os escritores deveriam mobilizar as duas mãos para manusear o rolo. É difícil imaginar um escritor de rolo produzindo seus textos e segurando o rolo de papiro ao mesmo tempo. Em conseqüência, a produção de uma obra, na Antigüidade, dependia de dois profissionais: o escritor, que elaborava os textos, e o escriba, que escrevia no rolo os textos ditados pelo escritor.

Entre os séculos II e IV da era cristã, a escrita passa a se inserir em um segundo cenário na medida em que uma nova e revolucionária forma de livro manuscrito vem substituir o livro em forma de rolo. Surgia, então, um novo suporte de escrita e de leitura chamado códice. Chartier (1999) descreve o códice como folhas de papiro dobradas e dispostas em cadernos, que eram costurados uns aos outros e encadernados de forma similar à do livro moderno. Tais cadernos substituíram progressivamente os rolos que, até então, carregavam a cultura escrita. O códice, como nova materialidade da escrita, transformou profundamente as formas de lidar com o texto. A partir de sua invenção, foi possível escrever e ler ao mesmo tempo, folhear uma obra, comparar duas ou mais obras abertas e localizar trechos a partir das páginas e dos índices, isso porque o códice permitia localização mais fácil e manipulação mais agradável do texto. Além disso, o códice permitiu que houvesse uma redução nos custos da fabricação do livro, isso porque possibilitou a utilização dos dois lados da página, a redução das margens e a reunião de um grande número de textos em volumes menores. No entanto, apesar de toda a evolução acarretada pelo surgimento do códice, a reprodução dos textos ainda era lenta e 
limitada, já que, assim como no rolo, os textos do códice também eram manuscritos.

No século $\mathrm{XV}$, uma outra grande revolução gerada pela invenção da imprensa - dá lugar a um terceiro cenário. Uma das principais características deste é a popularização do acesso às obras literárias. Até então, só era possível reproduzir um texto copiando-o à mão, mas a nova técnica inventada por Gutenberg, baseada em tipos móveis e na prensa, abriu, na história do Ocidente, a possibilidade inédita de multiplicação de textos. A partir dessa possibilidade, profissionais do texto, como tipógrafos, impressores, livreiros, corretores e editores surgiram e se tornaram importantes na confecção e reprodução das obras. Para Chartier (1999), contudo, a invenção de Gutenberg não foi uma revolução tão radical quanto se diz, e a razão para isso reside no fato de que, embora admitindo a importância de Gutenberg e de todas as transformações decorrentes da invenção da imprensa, Chartier (1999) leva em conta principalmente as características estruturais dos suportes textuais e alega que um livro manuscrito e um livro pós-Gutenberg se baseiam nas mesmas estruturas fundamentais do códice: distribuição do texto na superfície da página, paginação, numerações, índices, sumários. Dessa forma, de seu ponto de vista, há uma continuidade muito forte entre a cultura do manuscrito e a cultura do impresso. Ainda segundo Chartier (2002), tal continuidade deixa de existir com o advento da "revolução digital", ocorrida no final do século XX. Surge, então, a tela do computador como suporte textual, e é inaugurada a era da escrita e da leitura on-line, que predomina no nosso quarto e último cenário. Na visão de Chartier (1999), a revolução digital gerou mudanças muito mais radicais do que a revolução da imprensa por diversos motivos. Entre esses motivos, estão os de que a tela do computador: (a) permite que qualquer texto seja lido ou escrito em um mesmo e único suporte textual; (b) gera o desaparecimento dos critérios imediatos, visíveis, e de materiais de classificação e hierarquização dos discursos (paginações, indexações, citações, notas de pé de página, capítulos ou anexos); (c) faculta o surgimento do hipertexto, ou seja, de um texto não linear, não seqüencial e repleto de links que remetem a outros textos, e (d) inaugura a possibilidade de diálogo entre leitores e escritores.

\section{O impossível se torna possível: leitores e escritores podem dialogar}

Nos rolos e nos códices (sejam estes os antigos códices manuscritos ou os livros impressos), não há a possibilidade de leitores e escritores se comunicarem. A materialidade dos rolos e códices permite que as opiniões e críticas dos leitores sejam inseridas somente em espaços secundários e limitados, ou seja, nos espaços deixados em branco no texto: margens, folhas em branco ou contracapa. Por isso, Chartier (1999) afirma que o papel do leitor de rolos e códices é periférico e marginal, não tendo o poder de alterar ou ameaçar o conteúdo do texto original. Como ele próprio afirma:

“...O leitor não pode insinuar sua escrita a não ser nos espaços virgens do livro... Se o leitor pretende, todavia, inscrever sua clandestinidade no objeto, ele só pode fazê-lo ocupando subrepticiamente, clandestinamente, os espaços do livro deixados de lado pelo escrito: contracapa do encadernamento, folhas deixadas em branco, margens do texto, etc. (Chartier, 1998, p. 103)”.

É a tela do computador como suporte textual que inaugura a possibilidade de diálogo (e/ou cooperação) entre escritores e leitores, diálogo esse que pode ocorrer no espaço do próprio suporte. Segundo Chartier (2002), essa inovação é tão radical que faz com que os leitores possam se transformar em co-autores, dado que seus comentários e intervenções podem chegar aos escritores rápida e
...O leitor não

pode insinuar sua escrita a não ser nos espaços virgens do livro... Se o leitor pretende, todavia, inscrever sua clandestinidade no objeto, ele só pode fazê-lo ocupando subrepticiamente, clandestinamente, os espaços do Iivro deixados de lado pelo escrito: contracapa do encadernamento, folhas deixadas embranco, margens do texto, etc.

Chartier 
Um blog é uma página da web onde um weblogger, também conhecido como blogger ou blogueiro, registra textos sobre assuntos que considera interessantes. diretamente, sem passar por intermediários como antes. A tela do computador como suporte textual permite que qualquer pessoa com acesso à internet possa publicar textos livremente e sem mediações, e a mesma tela permite que o escritor peça a colaboração do leitor que pode, agora, intervir no próprio conteúdo do texto. Essa é a razão pela qual Chartier (2002) afirma que leitores e autores se confundem e se fundem em um mesmo suporte material. A tela e a internet fazem surgir espaços textuais públicos - como os fóruns de discussão, as famosas salas de batepapo, os espaços de trocas instantâneas de mensagem (a exemplo do ICQ ou do MSN Messenger), e os blogs - dos quais todos podem participar.

Poucos desses ambientes, no entanto, são espaços para a divulgação, aberta a comentários e sugestões dos leitores, de textos que guardam alguma semelhança com textos impressos como crônicas, contos, romances, biografias, poesias (a maioria dos espaços textuais públicos mencionados acima se caracteriza pela simples troca de mensagens). Um desses ambientes nos quais são divulgados textos completos que podem ser comentados pelos leitores é o dos blogs, e sobre ele aprofundaremos a investigação no que se segue. São dois os principais questionamentos que nos guiam nessa investigação. A revolução digital realmente fez surgir um novo tipo de relacionamento entre escritores e leitores? Estarão os leitores, através de seus comentários, críticas e sugestões, de fato participando da produção dos textos que circulam on-line?

\section{Travando contato com $o$ mundo dos blogs}

O termo weblog, posteriormente reduzido para blog, foi criado por Jorn Barger, editor do site Robot Wisdom (www. robotwisdom.com), em 1997 (Lemos, 2002).
Um blog é uma página da web onde um weblogger, também conhecido como blogger ou blogueiro, registra textos sobre assuntos que considera interessantes. O autor do blog adiciona a publicação mais recente, também chamada de post, no topo da página. Abaixo ou acima do post, podemos encontrar a data e a hora da publicação. Além disso, também é comum encontrarmos, abaixo de cada texto publicado, o nome ou o apelido do autor do blog. Dessa forma, os leitores podem acompanhar o blog lendo as publicações de forma cronologicamente inversa, ou seja, sempre da publicação mais recente para a mais antiga.

Os blogs estão entre os mais recentes espaços textuais na rede, mas já são densamente habitados. As facilidades na confecção e na manutenção, assim como as possibilidades que os autores dos blogs têm de publicar textos e imagens sem restrições, contribuíram para a rápida popularização dessas páginas.

O sucesso dos blogs, entretanto, não se deve apenas às facilidades na confecção e na manutenção. O link chamado comentários também foi um dos grandes responsáveis pelo êxito e popularidade dos blogs. Esse link, ao ser clicado, abre uma janela na qual os leitores podem fazer comentários, críticas ou sugestões a respeito dos textos lidos. Nessa mesma janela, os escritores também podem responder aos comentários dos leitores e interagir com eles. Os comentários vão sendo acumulados em ordem cronologicamente inversa e podem ser lidos não somente pelo autor do blog, mas também por qualquer usuário que clicar no link e abrir a janela dos comentários.

Os blogs começaram a se popularizar no Brasil entre 2000 e 2001, e rapidamente conquistaram inúmeros adeptos. No início de sua difusão em território nacional, os blogs caracterizavam-se, principalmente, como uma espécie de diários virtuais, nos quais seus autores escreviam sobre suas próprias 
experiências, sentimentos, projetos, etc. Atualmente, no entanto, além desses blogs que ainda constituem um espaço para a escrita de si (ver Lemos, 2002; Prange, 2002; Oliveira 2002, 2003), existem outros tipos de blogs. Um desses novos tipos é constituído pelos blogs de cunho jornalístico, que podem ser independentes ou associados aos grandes jornais (ver Schittine, 2004; Recuero, 2003a, 2003b; Silva, 2003). Outro tipo de blog, que vem se difundindo rapidamente, é formado pelos chamados blogs literários que, segundo seus próprios autores, funcionam como um espaço de criação, publicação e divulgação de seus textos literários.

Como vemos, os blogs podem ter características diferentes, mas, em praticamente todos os casos, contemplam a possibilidade de interação entre os autores e seus leitores a partir do link de comentários. Como seus autores vêem tal possibilidade? Realmente dela fazem uso?

\section{A pesquisa}

Para obter respostas para essas perguntas, necessitávamos dar voz aos autores de blogs. Precisávamos saber o que representava, para eles, manterem um blog, serem lidos e, principalmente, interagirem com seus leitores. Para tanto, foi realizada uma pesquisa qualitativa, que tomou como base blogs brasileiros atualizados freqüente e regularmente.

\section{Metodologia}

\section{Participantes}

Para selecionar os participantes desta pesquisa, foram estabelecidos alguns critérios de recrutamento: (a) Todos os participantes deveriam ser brasileiros, isso porque julgamos que uma amostra composta por brasileiros e estrangeiros poderia resultar em uma heterogeneidade inadequada para este estudo; (b) todos os participantes deveriam ser adultos (na realidade, como veremos a seguir, suas idades variaram entre 27 e 42 anos); (c) para que fosse possível apreender os impactos dos blogs na vida dos seus autores, todos deveriam ter seus blogs há no mínimo um ano; (d) os participantes selecionados deveriam manter seus blogs atualizados e renovar seus posts e imagens ao menos semanalmente; (e) os blogs de todos os participantes deveriam apresentar a seção de comentários, de modo a tornar possível a interação entre leitores e autores e também entre leitores e leitores. Não foram feitas quaisquer restrições quanto a sexo ou profissão.

Com base nesses critérios, foi feito o recrutamento dos participantes da pesquisa. Para tanto, foram enviados e-mails individuais a vinte autores de blogs, convidando-os a participarem da pesquisa. Recebemos respostas de dezesseis autores, mas somente nove deles - seis homens e três mulheres de fato nos concederam entrevistas. Caso fosse necessário, estávamos dispostas a repetir o convite a outros autores, mas tal necessidade não se materializou, como será discutido na seção de resultados.

Era o seguinte o perfil dos nossos participantes. Um tinha 30 anos e trabalhava como bancário e webwriter (embora fosse formado em jornalismo); dois tinham 37 anos, sendo que um era funcionário público (oficial de justiça) com curso superior incompleto, e o outro era bancário e formado em Direito. Outros dois eram jornalistas: um deles tinha 27 anos, e a outra, 42 (esta tinha pós-graduação em Arte e Filosofia). Entre os participantes, havia também dois advogados, ambos com 27 anos, uma com pós-graduação em Direito do consumidor e o outro, em Direito empresarial. O oitavo entrevistado tinha 28 anos, era formado em gestão de negócios internacionais e era editorchefe de um portal. A nona e última entrevistada tinha 40 anos e era diretora de conteúdo web (não tinha formação superior). 
Dos nove entrevistados citados, três eram do Rio de Janeiro (RJ), quatro de São Paulo (SP), um de Juiz de Fora (MG) e um de Brasília (DF).

Todos os entrevistados tinham seus blogs há pelo menos um ano. A todos foram atribuídos nomes fictícios para a preservação de seu anonimato. No entanto, tal preservação não foi considerada relevante pelos participantes desta pesquisa, já que, quando fizemos menção ao anonimato, a maioria disse que estar constantemente exposto fazia parte da rotina de um autor de blog.

Coleta de dados

Os dados foram coletados por meio de entrevistas individuais de cerca de uma hora e meia de duração cada. Todas as entrevistas foram realizadas pela internet, e os programas escolhidos pelos entrevistados foram o ICQ (I seek you) ou MSN Messenger. Ambos são programas de trocas instantâneas de mensagens que permitem bate-papos on-line e em tempo real, com uma linguagem simplificada e rápida. A realização das entrevistas via internet se deu devido à facilidade do acesso aos entrevistados. De fato, os primeiros contatos com os participantes já haviam sido feitos on-line, por meio da seção de comentários de seus blogs ou por e-mails individuais. Além disso, o ICQ e o MSN também facilitaram a realização das entrevistas, já que, enquanto as pesquisadoras moravam no Rio de Janeiro, a maioria dos participantes morava em outras cidades. Todos os entrevistados dominavam muito bem as ferramentas de bate-papo e demonstraram estar muito à vontade nas entrevistas virtuais. Tanto a construção do roteiro como as diretrizes para sua aplicação seguiram os princípios do Método de Explicitação do Discurso Subjacente (MEDS), proposto por Nicolaci-da-Costa (no prelo; ver, também, Nicolaci-da-Costa, 1989, 1994). Assim sendo, como instrumento de coleta de dados, foi usado um roteiro estruturado composto de itens a partir dos quais deveriam ser formuladas as perguntas durante a própria entrevista. $\mathrm{O}$ uso de itens, e não de perguntas prontas, visava $a$ preservar as características de conversas informais (perguntas prontas tendem a parecer artificiais). Também de acordo com as diretrizes do MEDS, esse roteiro estruturado era aplicado de forma flexível durante as entrevistas. Com isso, queremos dizer que a ordem dos itens podia ser alterada de modo a manter o fluxo de associações do entrevistado e perguntas de aprofundamento (do tipo “por que?”, “como assim?”, “dá para explicar melhor?”) podiam ser introduzidas sempre que necessário.

$\mathrm{O}$ roteiro era dividido em duas partes. A primeira era composta de perguntas objetivas sobre os participantes, tais como: idade, escolaridade, profissão, ocupação, etc. Já a segunda parte era composta por onze itens/ perguntas de cunho mais subjetivo, que abordavam os seguintes tópicos: (1) a decisão de criar um blog, (2) a freqüência de atualização dos posts, (3) a importância dos comentários recebidos, (4) a reação às críticas feitas nos comentários, (5) a falta de comentários, (6) o que o (a) entrevistado(a) achava atraente em um blog como leitor(a), (7) o que achava que atraía seus leitores, (8) como era o(a) entrevistado(a) no blog, (9) como era o(a) entrevistado(a) fora dele, (10) o papel do blog na vida do entrevistado(a), e (11) as mudanças que ocorreram em sua vida e nele(a) próprio(a) após a criação do blog.

Análise dos dados

Todo o material coletado foi analisado com base nas técnicas do MEDS (Nicolaci-da-Costa, $2007,1989,1994)$. No caso de entrevistas tradicionais (gravadas em áudio), o MEDS prevê uma primeira etapa que consiste da transcrição das entrevistas. Como, no caso da presente pesquisa, o material já se apresentava por escrito, a análise propriamente dita podia ser iniciada imediatamente. 
Também de acordo com o MEDS, a análise deve ser dividida em duas etapas. A primeira é chamada de análise interparticipantes. Nesta, todas as respostas de todos os entrevistados foram reunidas a partir dos itens/perguntas feitos. Sendo assim, todas as respostas dadas por todos os entrevistados ao primeiro item/ pergunta foram analisadas como um bloco. Esse procedimento foi adotado com todos os itens/ perguntas, até que todos os depoimentos de todos os participantes fossem analisados. Dessa forma, foi possível termos uma visão panorâmica dos depoimentos, ao mesmo tempo em que as respostas recorrentes nos discursos analisados já indicavam os primeiros resultados. Durante a segunda etapa da análise, chamada de intraparticipantes, cada entrevista foi analisada separadamente. Nessa etapa, procuraram-se possíveis inconsistências ou contradições nos discursos de cada participante, pois, segundo o MEDS, essas inconsistências e/ou contradições são uma excelente via de acesso ao discurso que jaz sob aquilo que é de fato dito.

\section{Resultados}

Como afirmamos anteriormente, estávamos receosas de que o número de autores de blogs que haviam aceitado participar da pesquisa fosse pequeno demais para que pudéssemos chegar a conclusões bem fundamentadas. Isso, no entanto, não ocorreu, na medida em que os discursos de nossos entrevistados rapidamente atingiram aquele que Bertaux (1981, citado por Seidman, 1998) chama de “ponto de saturação”, ou seja, o ponto em que, após um certo número de entrevistas, o entrevistador começa a ouvir, de novos entrevistados, relatos muito semelhantes àqueles que já ouviu, com uma rarefação de informações novas (Seidman, 1998; Nicolacida-Costa, 2007). Os resultados que se seguem foram, portanto, baseados nos depoimentos dos nove entrevistados mencionados acima.

\section{$\mathrm{O}$ que os entrevistados desejam com seus blogs}

De uma ou outra forma, todos os entrevistados revelaram que os principais motivos que os levaram a criar seus blogs foram o desejo de publicar textos livre e despretensiosamente, e, principalmente, o de saber as opiniões dos leitores sobre os textos publicados. Examinemos de perto cada um desses dois motivos.

O fato de publicarem seus textos livremente, de escolherem seus temas e, principalmente, de não se sentirem pressionados a publicar com uma determinada freqüência sobre um tema pré-estabelecido traz, aos nossos entrevistados, uma intensa sensação de prazer e também de autoridade e independência. Eles sentem-se livres para publicar o que, como, quando e com a freqüência que quiserem. Tal prazer sem obrigação foi, entre outros, revelado por Maíra, que somente publica textos em seu blog quando sente vontade. Como ela mesma diz:

“... Não faço disso [publicar textos no blog] uma obrigação... o blog é uma coisa que eu atualizo por prazer, não sou remunerada por ninguém pra isso eu nunca me obrigaria (nem que fosse de mim para mim) a fazer algo sem estar com vontade a não ser que fosse trabalho, e não é trabalho...” (Maíra, 27 anos, advogada).

São vários os entrevistados que, tal como Maíra, dão a entender que a liberdade de expressão é a grande responsável pela sensação de prazer que experimentam. Muitos afirmam encontrar, em seus blogs, uma liberdade de escrever o que pensam, sentem e/ou imaginam, que é, grande parte das vezes, tolhida pelos meios de comunicação e pelos editores. Escrever sem restrições ou regras préestabelecidas é, portanto, um grande atrativo que os blogs oferecem. Como afirma Eros:
"... Não faço disso [publicar textos no blog] uma obrigação... o blog é uma coisa que eu atualizo por prazer, não sou remunerada por ninguém pra isso eu nunca me obrigaria (nem que fosse de mim para mim) a fazer algo sem estar com vontade a não ser que fosse trabalho, e não é trabalho..."

Maíra, 27 anos advogada 
"...Sentique poderia usar o blog como uma ferramenta para descobrir

possibilidades de comunicação com outras pessoas - além de exercitar a escrita..."

Mota, 27 anos, jornalista
"O blog é uma ferramenta fantástica: vc escreve o que quer, como e quando quer escrever... se vc trabalha num jornal e quer escrever sobre um determinado assunto... um assunto interessante, mas num veiculo de comunicação, voce precisa obedecer uma pauta, uma linha editorial... o blog permite que você simplesmente escreva, sem obeceder nenhuma regra pré-estabelecida.” (Eros, 40 anos, diretora de conteúdo web).

Dora, que tem 42 anos e é jornalista, também fala sobre a liberdade que os blogs oferecem: “O principal objetivo [para ela manter um blog] era e ainda e' ter um espaco de liberdade para publicação. somos jornalistas, estamos acostumadas a publicar, mas nao com a liberdade de escrever o que quisermos." (Dora, 42 anos, jornalista).

Vários usam esse espaço para tentar criar coisas novas. Fox, por exemplo, diz que “[o blog é] um recanto virtual no qual exponho minhas idéias pessoais.” (Fox, 30 anos, bancário e webwriter).

Dar asas à criatividade é uma das razões pelas quais praticamente todos procuram se afastar do formato “diário adolescente” que caracterizou os primeiros blogs brasileiros (Prange, 2002). Este é o caso de Franco e Eros:

“... Tento transformar o que seria um diarinho num outro formato - seja ele qual for - que difira do diário puro e simples... gosto de criar” (Franco, 27 anos, advogado).

... Achei que [o blog] era uma ferramenta que só adolescentes iriam gostar e jamais pensei que eu ia engrenar nisso... na época, o blog foi criado para a faixa etária, em formato de ‘querido diário'. um formato alias, que foi se modificando com a entrada de gente (como eu) que viu no blog uma alternativa de mostrar seus textos despretensiosamente... (Eros, 40 anos, diretora de conteúdo web).
Além da publicação de textos, da liberdade de expressão e da sensação de prazer, outro motivo que, como já mencionado, os participantes da pesquisa apontaram como importante para a criação e manutenção de seus blogs é a possibilidade de saber a opinião de seus leitores. Em sua visão, o blog é um ambiente propício, não somente para publicar com liberdade mas também para interagir com os leitores e conhecer pessoas. Vejamos alguns dos depoimentos que coletamos.

Como vimos acima, Fox (30 anos, bancário e webwriter) afirma usar seu blog para divulgar links e fazer experimentações literárias. Além disso, Fox revela que seu blog é um espaço no qual interage com outras pessoas.

Eros, Mota, Júlio e Ítalo, entre outros, também fazem afirmações análogas.

“...Com o blog, também faço amizades, trocas, leio gente interessante, procuro conhecê-las.” (Eros, 40 anos, diretora de conteúdo web).

“...Senti que poderia usar o blog como uma ferramenta para descobrir possibilidades de comunicação com outras pessoas - além de exercitar a escrita...” (Mota, 27 anos, jornalista).

“Tinha muito excesso de material para publicar e quis ver o que as pessoas que eu admirava achavam de tudo aquilo.” (Júlio, 37 anos, bancário).

“... [me atraiu no blog] o fato de começar a ter contato com pessoas de todos os lugares..." (Ítalo, 37 anos, funcionário público).

Como já foi dito, essa interação entre os autores dos blogs e seus leitores ocorre na seção de comentários. Por isso mesmo, para aprofundarmos nossa compreensão sobre o que acontece nessa seção, é preciso que examinemos mais de perto o que nossos entrevistados dizem sobre ela. 
A importância explicitamente atribuída à seção de comentários

Em seus depoimentos, os participantes deixam clara a importância que dão à seção de comentários e discorrem sobre os modos como lidam com os comentários que recebem.

Fox, por exemplo, fala a respeito dos comentários como termômetro de aceitação ou de popularidade. Ele diz que os comentários desempenham um papel muito relevante nos blogs:

"Um dos grandes diferenciais na publicação de textos na Web está na imediata repercussão que eles ganham ao entrar no ar. Os primeiros feedbacks chegam poucos minutos após a publicação de um novo texto. Comentários complementam os textos com novos dados, novos pontos de vista, novas argumentações. Além disso, a quantidade de comments [comentários] recebidos serve para que eu saiba qual foi a aceitação do que eu escrevi, se o texto agradou ou não.” (Fox, 30 anos, bancário e webwriter).

Já Ítalo afirma direcionar seu blog a partir dos comentários que recebe:

"[o comentário] serve como termômetro pra saber se estou sendo abusado, se estou indo em direção errada, se devia mudar algo.” (Ítalo, 37 anos, funcionário público).

Além de indicar aceitação e popularidade, os entrevistados acreditam que a seção de comentários é a peça-chave para o estabelecimento de suas relações interativas com os leitores. Mota fala sobre isso da seguinte forma:

“A importância [dos comentários] é total. É a forma mais simples de estabelecer um 'elo' com as pessoas que se identificam com o tema... O que faz a diferença é a 'rede' de contatos onde o blog se insere. E entre todas as formas em estabelece-los (links, e-mails e afins), a caixinha de comentários é a mais eficiente.” (Mota, 27 anos, jornalista).

Dora é outra entrevistada que menciona a relação possível de se estabelecer com os leitores através dos blogs. Para ela, essa relação é o grande atrativo dos blogs. Em suas próprias palavras, a seção dos comentários é: "fundamental, sem os comments, nao haveria blog, a grande graca e' conversar com os leitores.” (Dora, 42 anos, jornalista).

Todos esses depoimentos sugerem que, para os participantes desta investigação, a seção dos comentários é imprescindível em seus blogs, dado que é através destes que podem estabelecer um diálogo com seus leitores e ouvir suas opiniões e sugestões. Uma análise mais aprofundada do material coletado nas entrevistas revela, entretanto, um quadro bem mais complexo.

\section{A importância implícita da seção de comentários: diferentes reações a críticas e elogios}

Nossos entrevistados, como acabamos de ver, afirmam que mantêm seus blogs porque querem ser lidos e comentados. É, porém, interessante observar que, tomados em conjunto, seus depoimentos revelam uma unanimidade: os comentários são somente bem-vindos se forem elogiosos. Examinemos alguns depoimentos de modo a explicitarmos como chegamos a essa conclusão.

Ítalo, por exemplo, diz que não responde às críticas de seus leitores, que ele chama de "detonação". Afirma, entretanto, que, muito embora seu blog seja muito popular e muito comentado, é raramente criticado: “... nao retruco mensagens de detonação [críticas], se bem que acho que nunca rolou" (Ítalo, 37 anos, funcionário público). Fica a pergunta de 
se é realmente possível que, entre os inúmeros comentários que ele diz receber, realmente não haja críticas...

Ricardo também afirma que a maioria dos comentários que recebe é composta por elogios. Ele diz que recebe algumas críticas, que analisa e respeita, mas admite que não gosta de ser criticado. Os comentários com elogios são por ele valorizados e vistos como mais relevantes. São, no entanto, ainda segundo ele, as críticas os comentários que realmente marcam:

“[os comentários são] super importantes... na maioria são elogios, outros são temas que gostaria de ser discutidos e uns pouco de reclamações... vc pode receber mil elogios, mas os que marcam são as criticas... afinal, ninguém gosta de ser criticado...” (Ricardo, 28 anos, editor-chefe de um portal na internet).

Maíra é ainda mais radical. Afirma ignorar as críticas:

“não ligo se alguém disser que não gostou de um texto meu, ou coisa parecida”. (Maíra, 27 anos, advogada).

Já Franco afirma literalmente que, apesar de alguns autores de blogs dizerem lidar bem com as críticas, eles gostam mesmo é de elogios. Franco afirma ser esse o seu caso. Diz que fica envaidecido quando os leitores comentam seus textos. Em contrapartida, ao receber uma crítica ou um comentário que discorda de um texto ou aponta alguma falha, Franco chama os leitores de “detratores” e diz odiar dar razão a estes. O depoimento de Franco mostra a posição subalterna que, no seu imaginário, os leitores ocupam em relação aos autores dos blogs:

“...eu fico envaidecido [com os comentários]... quando falam mal porque eu errei, e eu vejo que errei mesmo, aí fico putaço... odeio dar razão aos meus detratores - e não acho que sou tão esquisito por isso, né?” (Franco, 27 anos, advogado).

Como podemos observar, os entrevistados não gostam das críticas e consideram os comentários com elogios os mais relevantes. Tais reações aguçam a curiosidade: qual será sua reação quando seus posts não são comentados?

\section{Quando o silêncio é praticamente inexistente}

O exame atento de seus depoimentos revela que, segundo nossos entrevistados, isso não acontece, ou acontece muito raramente. Dito de outro modo, nossos entrevistados sugerem que, em seus blogs, os leitores raramente ficam em silêncio.

Fox chega a fazer referência a um número mínimo de comentários que seu blog recebe:

“... o caso é que nenhum post do Pensar Enlouquece fica sem pelo menos uma dúzia de comentários.” (Fox, 30 anos, bancário e webwriter).

Dora também afirma que a ausência de comentários é rara em seu blog. Segundo ela, além de sempre haver comentários, estes são interessantes e de alto nível:

“olha, eh muito raro o silencio. a gente [o blog era escrito por Dora e uma amiga] ficou conhecida logo no comeco, e sempre teve comments...mas somos privilegiadas por 2 razoes: sempre tivemos muitos comments e sempre foram de altissimo nível”. (Dora,42 anos, jornalista).

Eros também nos fala da sua relação com o silêncio e dos possíveis significados deste. Ela afirma não se lembrar de nenhuma publicação que não tenha sido comentada em seu blog: 
bom... eu não sei... mas pode ser qualquer coisa... pode ser que ninguem tenha gostado...mas isso tambem é um “comentário”, não é? não deixa de ser um feed back... eu to aqui tentando me lembrar de algum post sem comment...acho que nunca tive um... todos meus post tem comentarios, nem que sejam um ou dois. (Eros 40 anos, diretora de conteúdo web).

A existência de comentários, principalmente comentários positivos, parece ser fundamental para nossos entrevistados. A falta de comentários, por parte de seus leitores, parece não fazer (ou não poder fazer) parte de suas realidades. Nas poucas vezes em que é registrada, a ausência de comentários é interpretada como uma forma de feedback.

\section{Interagindo ou ouvindo ecos?}

Até agora, pudemos observar como, de acordo com o discurso dos nossos entrevistados, a seção de comentários é imprescindível, dado que é através dela que, além de avaliar sua aceitação e/ou popularidade, eles interagem com seus leitores. Uma leitura mais minuciosa de seus depoimentos mostra, porém, que a prática de nossos entrevistados não parece ser consistente com aquilo que dizem em seu discurso "oficial” sobre os blogs. O fato é que os entrevistados deste estudo, em sua grande maioria, indiretamente revelam não interagir com seus leitores na medida em que não dão respostas aos comentários que recebem!

Um bom exemplo é Dora, que, como observado anteriormente, afirma textualmente que, sem os comentários, seu blog não existiria, dado que seu principal objetivo é conversar com os leitores. Em outro ponto da entrevista, a mesma Dora entra em contradição consigo mesma e revela não acreditar que os leitores acessem blogs para conversar com os autores, mas sim, para conversar entre eles mesmos. É assim que justifica o fato de não responder aos comentários de seus leitores. Vejamos o que ela diz, em suas próprias palavras:

“[vc responde aos comentários?] nao necessariamente a todos. as pessoas nao estao la [na seção de comentários do blog] para conversar com a gente, mas principalmente para conversar entre si...” (Dora, 42 anos, jornalista).

O mesmo desinteresse em responder aos comentários feitos por seus leitores está presente no depoimento de Fox. Este diz responder quando é possível, pois, de acordo com ele mesmo, seu blog recebe muitos comentários:

"[respondo] quando possível. Tenho sérios problemas com falta de tempo para responder todos os e-mails que recebo. Imagine, então, se eu começar a responder a todos os comentários, um por um, sendo que há... posts que receberam mais 70 comentários.” (Fox, 30 anos, bancário e webwriter)

Já Maíra diz que costumava responder aos comentários, no início. Atualmente, ela sequer considera os comentários indispensáveis, como fazia antes, e muito menos ainda considera imprescindível dar respostas aos seus leitores. Admite fazer isso somente quando acha que o comentário merece uma resposta.

“no começo, lá atrás, era muito legal, tinha muito comentário e os próprios comentaristas acabavam ficando amigos e tal. Atualmente, eu gosto [dos comentários] mas não é nada imprescindível.” (Maíra, 27 anos, advogada).

De modo análogo, apesar de também dizer que um dos motivos para manter seu blog é o diálogo com os leitores, o desinteresse que Franco demonstra ter por esse diálogo é surpreendente. Ele afirma que, além de faltarlhe tempo, falta-lhe paciência para responder aos comentários que recebe: “... falta tempo e um pouco de saco, confesso.” (Franco, 27 anos, advogado). 
É minimamente intrigante perceber que a seção de comentários, inicialmente descrita como um espaço propício para a interação, em um segundo momento, possa ser encarada apenas como um espaço no qual os autores dos blogs somente recebem comentários aos quais não oferecem respostas. Será isso tudo o que essa incoerência tem a nos revelar?
Se, em um primeiro momento, os motivos alegados pelos próprios entrevistados para manterem seus blogs eram os de publicar livremente e dialogar com seus leitores e, como acabamos de ver, na prática, os mesmos entrevistados demonstram desinteresse nesse diálogo, emerge uma pergunta: é a possibilidade de publicar livremente a única responsável pela manutenção dos blogs por nossos entrevistados?

Julio (37 anos, bancário) faz uma declaração radical que parece responder afirmativamente a essa pergunta. Diz: “Não me vejo escrevendo para um público... Escrevo apesar do público.” (nossa ênfase).

É minimamente intrigante perceber que a seção de comentários, inicialmente descrita como um espaço propício para a interação, em um segundo momento, possa ser encarada apenas como um espaço no qual os autores dos blogs somente recebem comentários aos quais não oferecem respostas. Será isso tudo o que essa incoerência tem a nos revelar? Estarão nossos entrevistados engajados somente em ouvir ecos de suas próprias palavras?

\section{A real importância dos comentários}

Cremos que seria precipitado afirmar que nossos entrevistados estão somente interessados nos ecos do que escrevem. $\mathrm{Na}$ realidade, os próprios participantes da pesquisa, aqui e ali, nos fornecem pistas da real importância que os comentários têm para eles.

Em primeiro lugar, parece-nos ser possível afirmar que os comentários - não importa que sejam elogiosos ou críticos - atuam como um incentivo para que os autores dos blogs continuem a escrever na medida em que são uma confirmação de que seus textos são lidos. Os elogios claramente exercem não só a função de confirmar sua aceitação e popularidade como também a de aumentar seu poder discursivo, ou sua autoridade, incentivando-os a continuarem a escrever. Já as críticas, por mais que possam incomodar, minimamente dão aos nossos entrevistados a certeza de que são lidos.

Não são as críticas que podem desestimular nossos entrevistados (e muito provavelmente muitos outros autores de blogs). É, sim, a ausência de comentários, negada por praticamente todos, que pode fazê-lo. Disso se dão conta pelo menos alguns entrevistados. Ítalo está entre eles.

Ele afirma que ficaria muito chateado se seus posts não fossem comentados e complementa que "talvez nem quisesse atualizar novamente...pq parece que ninguem te deu atençao naquele momento...” (Ítalo, 37 anos, funcionário público).

Júlio complementa com uma visão positiva em relação ao silêncio. Diz: “A ausência é sempre um incógnita. Nessas horas, me ponho como um leitor e imagino, otimistamente, que gostaram tanto que ficaram sem palavras.” (Júlio, 37 anos, bancário).

Os depoimentos apresentados sugerem o que pode estar acontecendo na maior parte dos casos (inclusive no de Júlio que, embora afirmando que escreve apesar do público, não parece dispensar este). Os participantes mostram que é essencial serem comentados.

\section{Um ambiente interativo onde falta interação}

Não há margem para dúvidas quanto ao caráter revolucionário da tela do computador como suporte textual. Diferentemente do que acontecia (e ainda acontece) no que diz respeito aos suportes textuais que a antecederam, a tela do computador (quando este está conectado em rede) de fato permite 
a interação entre leitores e escritores, e essa interação realmente acontece em diversos tipos de ambiente (como nos fóruns de discussão ou nas salas de bate-papo), nos quais - embora as características da escrita, da leitura e da interação possam ser diferentes entre si - escritores e leitores se confundem e trocam constantemente de posição, como em um verdadeiro diálogo.

Talvez exatamente por essa razão tenha sido criada uma expectativa (Chartier, 2002) de que a escrita espontaneamente disponibilizada em um ambiente (tecnologicamente) interativo como os blogs, no qual um espaço é explicitamente destinado ao diálogo entre escritores e leitores, fosse gerar um novo tipo de escrita colaborativa ou, ao menos, um diálogo entre leitores e escritores que pudesse vir a exercer alguma influência no trabalho dos últimos.

Ao que os nossos resultados indicam, no entanto, isso nem sempre acontece mesmo quando, em um discurso que procura corresponder a essa expectativa, os próprios escritores admitem que poderiam se beneficiar de um diálogo com seus leitores. Vemos algumas possibilidades de explicação para essa contradição.

A primeira se fundamenta em uma importante diferença que existe entre os fóruns de discussão, as salas de bate-papo, os espaços para trocas de mensagens instantâneas (ICQ e MSN Messenger) e os blogs. Enquanto, nos primeiros, o principal objetivo dos freqüentadores é dialogar, nos blogs, esse objetivo é secundário. Como foi mencionado anteriormente, os blogs permitem que qualquer usuário da internet se torne um autor e publique seus experimentos literários sem qualquer tipo de interferência ou censura. Talvez esses novos autores desdenhem as críticas de seus leitores justamente porque as vêem como uma expressão da censura da qual pensavam estar livres. De forma análoga, talvez esses escritores também evitem interagir com seus leitores por perceberem tal interação como uma interferência desnecessária em seu trabalho.

Outra possibilidade a ser cogitada é a de que a autoria de textos cuja divulgação não passa por qualquer tipo de intermediário alimente, nos escritores de blogs, uma noção bastante presente tanto na mídia convencional como na internet, nos últimos tempos. Referimo-nos à noção, tão divulgada nos reality shows, de que aquilo que qualquer um de nós faz e é pode ser do interesse de muitos outros. Daí advém o sucesso do YouTube (website que permite que seus usuários carreguem, assistam e compartilhem qualquer tipo de vídeo em formato digital), cuja difusão está calcada numa frase de efeito - Broadcast yourself - que nos incentiva a divulgar o que somos. Caso essa tendência se alastre (os reality shows continuam proliferando...), podemos estar diante de um processo de recrudescimento do individualismo, individualismo esse que uma participante de outra pesquisa realizada com escritores de blogs (Di Luccio, 2003) chamou de "umbiguismo".

Ainda outra possível razão - que não exclui nenhuma das anteriores - para a ausência de interação observada nesta pesquisa é a de que, como mostra a literatura (ver Nicolaci-da-Costa, 1987), quando as mudanças externas são muito rápidas, somos incapazes de absorvê-las de imediato. Tal constatação nos leva a pensar que a falta de diálogo entre os nossos entrevistados e seus leitores pode residir no fato de que ainda não nos encontramos - eles e nós - muito distantes da cultura impressa, esta que, como sabemos, tem, como uma de suas características, o fato de produzir textos que são intocáveis uma vez prontos, e que vêm sistematicamente migrando para a tela (isso pode ser facilmente observado nos inúmeros jornais on-line, nos artigos científicos disponibilizados em bibliotecas e periódicos virtuais, nos documentos salvos em formato 
PDF de forma a não poderem ser alterados, etc.) Juntamente a essa cultura, vêm suas definições do que é ser um escritor e do que é ser um leitor bem como suas atribuições de autoridade ao primeiro e de (relativa) receptividade ao segundo. Vêm também as expectativas de que leitores geralmente se manifestam para elogiar e são mal recebidos pelos escritores quando criticam.

Enfatizamos, contudo, que essas são apenas conjecturas. Não há como darmos uma resposta conclusiva para a contradição que nossa pesquisa trouxe à tona. Deixamos tal tarefa para outros investigadores - ou, quiçá, para nós mesmas - em outras investigações. 
BARGER, J. Weblog resources FAQ. setembro 1999. Disponível em: $<$ http://www.robotwisdow.com/weblogs $>$.

CHARTIER, R. Formas e sentido. Cultura escrita: entre distinção e apropriação. Campinas, São Paulo: Mercado de Letras; Associação de Leitura do Brasil (ALB), 2003.

2002

Os desafios da escrita. São Paulo: Editora UNESP,

Cultura escrita, literatura e história: conversas de Roger Chartier com Carlos Aguirre Anaya, Jesús Anaya Rosique, Daniel Goldin e Antonio Saborit. Porto Alegre: ARTMED Editora, 2001.

A aventura do livro: do leitor ao navegador. São Paulo: Editora UNESP, 1999

A ordem dos livros: leitores, autores e bibliotecas na Europa entre os séculos XVI e XVIII. 2 ed. Brasília: Editora Universidade de Brasília, 1998

Forms and meanings: texts performances and audiences from codex to computer. Philadelphia: University of Pennsylvania Press, 1995.

CHARTIER, R.; Paire. A. Práticas da leitura. São Paulo: Estação Liberdade, 1996

DI LUCCIO, F. Blogs: um novo fenômeno lingüístico e a construção de novas identidades. Monografia final do Curso de Pós-Graduação em Formação de Professores de Português para Estrangeiros. PUC-RJ, dezembro de 2003

LEMOS, A. A arte da vida. Diários pessoais e webcams na Internet. Revista de Comunicação e Linguagem, Lisboa, 2002.

NICOLACI-DA-COSTA, A. M., O campo da pesquisa qualitativa e o método de explicitação do discurso subjacente (MEDS). Psicologia: Reflexão e Crítica, Porto Alegre, 2007.

A análise do discurso em questão. Psicologia: Teoria e Pesquisa, Brasília, v.10, n. 2, p.317-331, 1994.
.Questões metodológicas sobre a análise do discurso. Psicologia: Reflexão e Crítica, v. 4, n.1, p. 103-108, 1989.

Sujeito e cotidiano: um estudo da dimensão psicológica do social. Rio de Janeiro: Editora Campus, 1987.

OLIVEIRA, R. M. C. De onda em onda: a evolução dos ciberdiários e a simplificação das interfaces. Biblioteca on-line de ciências da comunicação. 2003. Disponível em: < http://www.bocc.ubi.pt/pag/ oliveira-rosa-meire-De-onda-onda.pdf $>$.

OLIVEIRA, R. M. C. Diários íntimos na era digital. Diários públicos, mundos privados. Ciberpesquisa. 2002. Disponível em: <http:// www. facom.ufba.br/ciberpesquisa/>.

PRANGE, A. P. L. Da literatura aos blogs: um passeio pelo território da escrita de si. Dissertação (mestrado em Psicologia clínica) Pontifícia Universidade Católica do Rio de Janeiro, Rio de Janeiro, 2002.

RECUERO, R. C. Warblogs: Os blogs, a guerra no Iraque e o jornalismo on-line. In: Revista Verso e Reverso: Revista da Comunicação. Porto Alegre, v. 37, p. 57-76, 2003a. Disponível em <http://

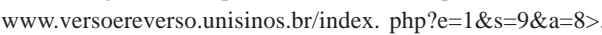

RECUERO, R. C. Weblogs, webrings e comunidades virtuais. In: 404notFound. V. 1, n. 31, 2003b. Disponível em: <http:// w w w. boc c.ubi.pt/pag/recue ro-raque l-w a rblogs.pdf\#search=\%22recuero\%20warblogs\%22 >.

SCHITTINE, D. Blog: comunicação e escrita íntima na internet. Rio de Janeiro: Civilização Brasileira, 2004

SEIDMAN, I. Interviewing as qualitative research: a guide for researchers in education and the social sciences. $2^{\mathrm{a}}$ ed. New York: Teachers College Press, 1998.

SILVA, J. A. B. Weblogs: múltiplas utilizações e um conceito. XXVI Congresso Anual em Ciência da Comunicação. Belo Horizonte, MG setembro de 2003.

\section{Referências}

